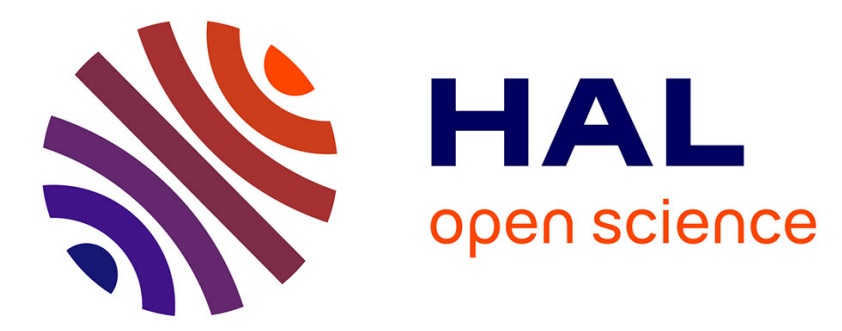

\title{
Designing multi-unit multiple bid auctions: an agent-based computational model of uniform, discriminatory and generalised Vickrey Auctions
}

Atakelty Hailu, Sophie Thoyer

\section{- To cite this version:}

Atakelty Hailu, Sophie Thoyer. Designing multi-unit multiple bid auctions: an agent-based computational model of uniform, discriminatory and generalised Vickrey Auctions. Economic Record, 2007, 83 (S1), pp.S57-S72. 10.1111/j.1475-4932.2007.00410.x . hal-02664994

\section{HAL Id: hal-02664994 \\ https://hal.inrae.fr/hal-02664994}

Submitted on 31 May 2020

HAL is a multi-disciplinary open access archive for the deposit and dissemination of scientific research documents, whether they are published or not. The documents may come from teaching and research institutions in France or abroad, or from public or private research centers.
L'archive ouverte pluridisciplinaire HAL, est destinée au dépôt et à la diffusion de documents scientifiques de niveau recherche, publiés ou non, émanant des établissements d'enseignement et de recherche français ou étrangers, des laboratoires publics ou privés. 


\title{
Designing multi-unit multiple bid auctions: An agent-based computational model of uniform, discriminatory and generalized Vickrey auctions
}

\author{
*Corresponding author \\ School of Agricultural and Resource Economics, \\ Univeristy of Western Australia \\ 35 Stiriling Highway, M089 \\ Crawley (Perth), WA 6009 \\ AUSTRALIA \\ email: ahailu@are.uwa.edu.au \\ phone: +61864882538 \\ fax: +61 864881098 \\ ** ENSAM -LAMETA \\ 2 place Viala \\ 34060 Montpellier cedex 1 \\ France \\ Email : thoyer@ensam.inra.fr \\ Phone +33(0)4 99612218 \\ $\mathrm{Fax}+33(0) 467545805$
}

Atakelty Hailu* and Sophie Thoyer** 


\title{
Designing multi-unit multiple bid auctions: An agent-based computational model of uniform, discriminatory and generalized Vickrey auctions
}

\begin{abstract}
Multi-unit auctions are being employed by public agencies to allocate resources and to purchase services. These auctions resolve the lumpy bid problem inherent in single-unit auctions by allowing bidders to submit a supply or demand schedule. However, the choice of pricing formats for multi-unit auctions is controversial. Neither economic theory nor laboratory experiments depict a complete picture of how alternative pricing formats perform in terms of budgetary outcomes or allocative efficiency. This paper constructs an agent-based computational model to compare uniform, discriminatory and generalized Vickrey formats under different degrees of competition and heterogeneity in the bidder population.
\end{abstract}

Key words: procurement auctions, multi-unit auctions, computational experiments, agentbased modelling, reinforcement learning

JEL: $C 900-D 440-Q 250$ 


\section{Designing multi-unit multiple bid auctions: An agent-based computational model of uniform, discriminatory and generalized Vickrey auctions}

\section{Introduction}

Multi-unit auctions are auctions in which the auctioneer wishes to sell or buy several units of the same good. They can be single-bid or multiple-bid auctions. Under the single-bid version, each individual bidder is allowed to submit a bid consisting of a single price-quantity pair bid. Multiple-bid auctions, on the other hand, allow bidders to bid with demand (or supply) schedules helping avoid the 'lumpy bid' problem inherent in single-bid auctions (Tenorio, 1993). Multi-unit multiple bid auctions are being increasingly used, with well known applications including wholesale electricity markets as well as markets for Treasury bills and foreign exchange (Tenorio, 1999). In the literature, the term multi-unit is mostly used to refer to the multi-unit multiple-bid auction. For the sake of brevity, we will use this shorter name in this paper.

In contrast to single-bid auctions for which the revenue equivalence theorem (RET) has been established $^{1}$, the design of multiple-bid auctions suffers from great uncertainty about the performance of alternative pricing formats. As a result, the choice between discriminatory (or pay-as-bid) and uniform price formats continues to be controversial both in Europe and in the United States (Binmore and Swierzbinski 2000). This is the case for US Treasury bill auctions, for which policy-makers have switched from discriminatory to uniform payment formats in the hope of improving allocative efficiency and budgetary revenues (Binmore and Swierzbinski 2000).

\footnotetext{
${ }^{1}$ The revenue equivalence theorem (RET) indicates that under the hypothesis of bidders' risk neutrality, and for private independent values, all payment formats lead to equivalent expected revenues for the auctioneer.
} 
The controversy exists because economic theory does not provide much guidance on the relative efficiency of alternative formats in a multiple-bid setting. The uncertainty is even greater when the bidder population is heterogeneous or when bidder marginal values (costs) are not constant (Ausubel and Cramton, 2002). Empirical studies are also scarce (Wolfram, 1998, Tenorio, 1993). The case for experimental and computational approaches to further our understanding of multiple-bid auction design is therefore strong (Binmore and Swierzbinski, 2000, p 407).

Laboratory and field experiments have provided more insights into the relative performance of the three payment formats (e.g. Alemsgeest, Noussair and Olson 1998, Kagel and Levin 2001, Engelmann and Grimm 2003). However, the complexity of these auctions means that the experiments are restricted to very simplified settings. To date, most of these studies have focused on auctions where two bidders with flat demand curves compete for two units. Computational experiments or agent-based computational economics (ACE), on the other hand, suffer less from the cost or complexity constraints that limit laboratory experiments. ACE provides a useful and inexpensive research tool for examining the performance of auctions under different contexts and for comparing the relative performance of different auction designs. A growing number of studies are employing ACE to complement theoretical and experimental studies in economics ${ }^{2}$.

This paper constructs an agent-based model to examine the performance of three alternative formats for multi-unit auctions: discriminatory, uniform and the generalized Vickrey. The simulated auction market is cast as a procurement auction where a government agent buys services from a population of bidders with private independent values reflecting different production capacities and different cost structures. Bidders submit supply functions indicating the amount of services they would provide at different prices. Auctions are repeated and

\footnotetext{
${ }^{2}$ Tesfatsion's web site at http://www.econ.iastate.edu/tesfatsi/ace.htm is an excellent source of information on ACE research in economics.
} 
bidders use reinforcement learning to update their individual bid functions with the objective of increasing their net incomes. The performance of each auction format is evaluated for different levels of competition ${ }^{3}$, with the demand level from the purchasing agency ranging in magnitude from $12.5 \%$ to $50 \%$ of the aggregate capacity of the bidders. The comparative analysis is also undertaken for different levels of heterogeneity in the size and cost structures of individual bidders.

The paper is organized as follows. We first briefly review the various auction formats and the structural properties of bidding strategies implied by theoretical analysis. In the third section, we develop an agent-based model (ABM) of boundedly rational bidders revising their bid choices using Erev and Roth's (1998) reinforcement learning algorithm. In the fourth section, we present the results from the computational experiments and compare bidding behaviours, budgetary outlays and efficiency of allocation for the three auction formats. The simulation results provide some confirmation of analytical predictions. But they also indicate that bidding behaviours display more interesting patterns depending on the interplay between the nature of heterogeneity in the bidder population, the intensity of competition, and the type of the auction. We demonstrate that under the generalized Vickrey format, simulated bids converge towards truthful bids as predicted by the theory and that bid shading is the rule for the discriminatory and the uniform auctions. Vickrey auctions have the best performance almost for all competition and heterogeneity levels studied here. The discriminatory auction has the worst performance for almost all levels of competition when marginal costs of supply are increasing. In the fifth section, we summarize the paper and draw some general recommendations.

\footnotetext{
${ }^{3}$ The level of competition here is measured as the ratio of demand by the government agency over aggregate supply by bidders. It reflects the degree of demand rationing but it does not include the impact of changes in the number of bidders.
} 


\section{Multiple-bid auctions}

We concentrate on the case of sealed-bid simultaneous auctions for the procurement of identical objects with private independent values. We assume that the number of units that the auctioneer wishes to buy is fixed and equal to $Q_{d}$. We compare the three most common payment formats: 1) the discriminatory payment (also known as pay-as-bid) in which bidders are paid an amount equal to the sum of their actual winning bids; 2) the uniform payment in which all units sold earn the clearing price equating aggregate supply to demand; and 3) the generalized Vickrey payment, which is a generalization of the second price payment in the unit auction case. Under the Vickrey, each winner is paid the amount corresponding to the sum of the bids (other than his own) that are displaced by his successful bids.

We will start by describing the allocation procedures under the three payments rules using the concept of residual demand. In a procurement multi-unit auction, each bidder submits multiple bids indicating the price he is willing to accept for different quantities. In effect, these multiple bids are equivalent to an inverse supply function. Let's define the supply schedule of bidder $i$ as $Q^{i}=S^{i}(b)$ with $Q^{i}$ the quantity that bidder $i$ is willing to sell for a per-unit price $b$.

The residual demand facing bidder $i, D^{-i}(b)$, is defined as the total demand $Q_{d}$ of the purchasing agency less the quantities supplied by all other bidders $j$ for each level of clearing price $b$.

$$
D^{-i}(b)=\max \left\{0, Q_{d}-\sum_{j \neq i} S^{j}(b)\right\}
$$

In the three auction formats, the allocation problem is solved by awarding each bidder the quantity $Q^{*_{i}}$ at which his supply schedule intersects his residual demand.

$$
Q^{*_{i}}=D^{-i}\left(b^{*}\right)=S^{i}\left(b^{*}\right)
$$


However, the three formats differ in the calculation of the payments for the winners. In the discriminatory auction, each bidder is paid the area under his supply schedule up to $Q^{* i}$. In the uniform-price auction, all units sold earn the clearing price $b^{*}$ equating aggregate supply to demand. Therefore, infra-marginal units receive payments that are higher than the corresponding bids. In a generalized Vickrey auction, each successful bidder is paid the entire area under the residual demand up to $Q^{*_{i}}$.

Theoretical investigations on multiple-bid auctions were initiated by Wilson (1979), who described the purchase of perfectly divisible units as "auctions of shares". Since then, there has been a rich literature on this mechanism, leading to two important and unchallenged conclusions. First, the revenue equivalence theorem, which indicates that all payment formats lead to equivalent expected revenues for the auctioneer, does not carry over to the multiplebid auction case (Tenorio, 1993; Engelbrecht-Wiggans and Kahn, 1998; Ausubel and Cramton, 2002). Second, most payment formats lead to multiple equilibria. It is therefore impossible to obtain equilibrium strategies as closed form expressions and authors have therefore focussed on the analysis of the structural properties of bidding strategies (Noussair, 1995; Krishna, 2002; Chakraborty, 2006).

Many empirical and theoretical studies compare the properties of bidding strategies under the three payment formats. Most studies - conducted for the case of a standard selling rather than procurement auction - predict that the uniform payment and the discriminatory payment lead to bid shading but that demand reduction can take different forms in the two auctions (see Table 1 for a summary).

In the uniform payment, Engelbrecht-Wiggans and Kahn (1998) and Ausubel and Cramton (2002) demonstrate that, although it is a dominant strategy to bid truthfully for the first unit 
(or, in the continuous case, when quantity tends to zero), it is efficient for bidders to shade their bids for additional quantities. Moreover, the amount of bid shading increases with quantities offered because "the incentive to win units at any price below marginal value is offset by the incentive to reduce the price paid on infra-marginal units that are won anyway" (Ausubel and Cramton, 2002, p23). The latter becomes increasingly important when quantities increase, which explains the increasing bid shading. This phenomenon has been verified experimentally by Kagel and Levin (2001) and empirically by Tenorio (1993) in his analysis of the Zambian foreign exchange market, as well as by Wolfram (1998) who conducted an econometric analysis of "incremental overbidding" in the electricity procurement auction in England and Wales. However, in a field experiment involving sports card auctions, List and Lucking-Reiley (2000) point out that, although bid-shading is observed, the first-unit bids are rarely sincere, contrary to theoretical predicitons.

The discriminatory payment leads to different, more complex, bidding strategies. Back and Zender (1993) demonstrate, in a simplified setting with two bidders and two units, that there is an incentive to submit flatter supply curves than in a uniform price auction. In other words, bidders overbid by relatively large amounts for the first unit compared to subsequent units. If bidders are risk neutral, submitting entirely flat supply curves, above the true opportunity cost curve, is a possible equilibrium. Krishna (2002) also shows, in the case of two units, that a strategy of differential bid shading, comparable to what is observed in the uniform payment, is also a possible outcome, when the difference in the marginal values of the two units is high. This is confirmed experimentally by Engelmann and Grimm (2003).

The generalized Vickrey payment or its counterpart in the open format (i.e. the ascending auction with "clinched" quantities designed by Ausubel, 2005) is the only multiple-unit auction in which truthful bidding is a weakly dominant strategy, resulting in efficient 
allocation $^{4}$. It was demonstrated theoretically (Ausubel and Cramton, 2002; Ausubel, 2005)

and tested experimentally (List and Lucking-Reiley, 2000; Engelmann and Grimm, 2003).

However, the generalized Vickrey is rarely employed in practice because the payment rule is not easily understood by bidders. Decision-makers therefore prefer to implement discriminatory or uniform payment auctions, although it is known that overbidding may lead to allocation inefficiencies.

Table 1: Structural properties of equilibrium strategies under different payment formats for multi-unit auctions.

\begin{tabular}{|l|l|}
\hline Sealed-bid format & Structural property of equilibrium strategies and efficiency \\
\hline Discriminatory & $\begin{array}{l}\text { Scope for "high flat supply" or for "incremental overbidding" } \\
\text { when true opportunity cost curve is steep; } \\
\text { Inefficient allocation }\end{array}$ \\
\hline Uniform-Price & $\begin{array}{l}\text { "Incremental overbidding"; Coordination at a high price } \\
\text { equilibrium; Inefficient allocation }\end{array}$ \\
\hline Generalized Vickrey & $\begin{array}{l}\text { Truthful bidding is a weakly dominant strategy; } \\
\text { Efficient allocation }\end{array}$ \\
\hline
\end{tabular}

Since there are different classes of equilibrium strategies, it is difficult to analyse how bidders coordinate or even compare the efficiency of the two payment formats. Therefore, it is crucial that more results be produced to help decision-makers to make a choice between discriminatory and uniform payments. In particular, it is particularly important to assess how these formats compare for different levels of competition and for different types of heterogeneity in the bidder population. It was demonstrated that increased competition leads to the reduction of strategic behaviour and to more truthful bidding (Swinkels 1999) but there is no indication whether this performance gain is greater in the uniform format or in the discriminatory format. There are two sources of bidders' heterogeneity which are worth exploring. The first one is heterogeneity in the supply capacity of bidders and the second is related to heterogeneity in supply costs. The theoretical literature does not provide answers on the impact of these types of heterogeneity. There is a need, therefore, to turn to experiments to

\footnotetext{
${ }^{4}$ Efficiency here refers to the social opportunity cost of the allocation of resources. An efficient reallocation is obtained when goods are bought (sold) from (to) bidders with the lowest marginal production costs (highest marginal utility).
} 
further our understanding in this area of research. Instead of using human experiments, which are costly to run, we chose to develop computational experiments.

\section{The modelling of bidding strategies with artificial learning agents}

ACE is the study of artificial societies of interacting autonomous agents that directly emulate the behaviours of individuals, institutions and environmental components that make up the market or the system being studied (Epstein and Axtell 1996; and Tesfatsion 2002). Tesfatsion in 2002 surveyed the research areas in which agent-based computational economics (ACE) has been applied. Duffy (2006) examines the relationship between ACE and human-subject experiments in economics and provides an overview of studies using ACE to examine findings from human subject experiments. Unlike conventional or deductive approaches, the starting point in ACE is the specification of agent attributes and behaviours rather than equations or equilibrium conditions describing the system under study. Therefore, ACE is suited to the study of systems where modelling outcomes can be gainfully enriched through the explicit incorporation of phenomena like agent heterogeneity, local interactions, networking, inductive learning, as well as through the relaxation of other restrictive assumptions that are normally imposed in theoretical analysis for tractability purposes (Tesfatsion 2002). Studies applying ACE to the study of auctions include Andreoni and Miller (1995), Nicolaisen, Petrov and Tesfatsion (2001), Bower and Bunn (2001), Bunn and

Oliveira (2001), Hailu and Schilizzi (2004). The model presented in this paper differs from previous models because it tackles the issue of multiple-bid auctions: competing bidders submit continuous bid supply functions in the auction and employ reinforcement learning algorithms to update their bidding strategies.

\section{Structure of agent based model}

Our auction model has a population of agents selling goods in a sealed-bid auction to a single buyer, the government agent. The government agent has a fixed target or demand level. Each 
seller is characterized by a (true) non-decreasing supply function and a given supply capacity indicating the maximum amount of good it has for sale. The government agent does not know the true supply functions of the different bidders and makes selection based on submitted or declared supply bid functions. Over time, sellers learn to choose, in a repeated process, the supply bid functions that maximize their expected net incomes.

Each auction round involves two stages. In the first stage, the government collects bid functions from the sellers, calculates the residual demand for each bidder and determines the equilibrium quantities bought from each of them at the intersection of their bid supply and their residual demand. In the second stage, payments to individual bidders are determined according to the auction format in use. Sellers use the results of the auction to compute their net incomes and to update the probabilities with which they choose their bid strategies for the next round. The strategy choice probabilities of a bidder therefore depend on his opportunity costs as well as on the history of choices he has made and rewards obtained for those choices.

For the sake of simplicity, it is assumed that the true supply function of each sellers $i$ is linear and can be written as:

$$
P_{i}=a_{i}^{0}+b_{i}^{0} Q_{i} \text { with } 0 \leq Q_{i} \leq m s_{i}
$$

where $m s_{i}$ is the capacity of bidder $i, a_{i}^{0}$ is his entry price and,$b_{i}^{0}$ is the supply slope.

\section{Seller choice strategies}

We make the simplifying assumption that the learnt bidding curve can be reasonably approximated by a linear curve. The learnt bid curve is therefore assumed to be represented as follows:

$$
\beta_{i}\left(Q_{i}\right)=a_{i}+b_{i} Q_{i} \text { with } \beta_{i}\left(Q_{i}\right) \text { the strategic bid of player } i
$$


There are therefore two dimensions to the seller's choice strategy: intercept choice $\left(a_{i}\right)$ and slope choice $\left(b_{i}\right)$. The learning algorithm described below will allow bidders to progressively explore different combinations of $a_{i}$ and $b_{i}$ and to retain the best values based on the performance of past bids. Intercept and slope choices are discretized into seven steps. For the slope parameter, for example, there is a choice of seven values equally spaced between 0 and the maximum slope value implied by the constraints discussed below. The true intercept $\left(\mathrm{a}^{0}\right)$ and slope $\left(b^{0}\right)$ parameters are included in the choice sets to allow for truthful revelation of supply function parameters.

A constraint is imposed on the choice of strategies so that the chosen bid function does not have any section falling below the true cost function (bidding below true costs is a dominated strategy and is therefore not included in the bidder's choice set). This is guaranteed by restricting the allowed or feasible parameter choices $(a$ and $b$ ) as shown in Figure 1. We also impose that bidders won't use extreme overbidding strategies by restricting their bids to less than three times the marginal cost of supply of the most expensive unit by the most expensive supplier. This is equivalent to imposing an implicit reserve price by the auctioneer.

\section{The learning algorithm}

Different learning models have been developed over the last several decades. A typology of learning models presented in Camerer (2003) shows the relationship between these learning algorithms and how certain variants are special cases of others. The models differ in terms of their information requirements. The reinforcement-learning algorithm is chosen for this study as it is particularly suitable for modelling bidding behaviour without requiring that players be knowledgeable about forgone payoffs associated with strategies that they did not select.

The reinforcement-learning algorithm was developed by Roth and Erev (1995) based on the reinforcement principle that is widely accepted in the psychology literature. Erev and Roth 
(1998) extend and use this learning algorithm to model behaviour from twelve experimental studies $^{5}$ of repeated games with unique nontrivial equilibria in mixed strategies. They find that the reinforcement learning model's predictions of the choices of experimental subjects generally outperform theoretical predictions. The Roth-Erev algorithm has been used in agent-based studies of electricity auction markets (e.g. Nicolaisen et al 2001; Bunn and Oliveira, 2001).

The algorithm is based on the following four principles rooted in the psychology of learning (Erev and Roth 1998): the law of effect, the power law of practice, experimentation and recency. The law of effect asserts that the tendency to choose an action is strengthened (reinforced) or weakened depending upon whether the action produces favourable results or not. This principle implies that choice is probabilistic. The power law of practice refers to the fact that learning curves tend to be initially steep. Experimentation (or generalization) implies that strategies similar to previously chosen successful ones will be employed more often. Experimentation prevents players from quickly being locked into particular choices. Recency (or forgetting) requires that recent experience has more impact on behaviour than past experience.

The main features of the algorithm can be described using the following three equations. If the propensity of player $i$ to choose strategy (a,b) at time $t$ is denoted by $q_{i}^{a b}(t)$, the propensity updating function can be written as (Erev and Roth 1998, p. 863):

$$
q_{i}^{a b}(t+1)=(1-\phi) q_{i}^{a b}(t)+E_{c d}(a, b, R)
$$

\footnotetext{
${ }^{5}$ Eleven of these games were conducted by different researchers in the period between 1960 and 1995.
} 
where: $\varphi$ is the recency parameter, $R$ is the reward or reinforcement from previous choice of strategy $(c, d)$ and is the payment above true costs (net revenue) obtained by the seller, while $\mathrm{E}_{\mathrm{cd}}(a, b, R)$ is the following three step generalization function ${ }^{6}$ :

$$
\begin{aligned}
& =\mathrm{R}(1-\varepsilon) & & \text { if } a=c \text { and } b=d \\
\mathrm{E}_{\mathrm{cd}}(a, b, R) & =\mathrm{R} .(\varepsilon / \mathrm{n}) & & \text { if }(a, b) \text { is neighboring strategy of }(c, d) \\
& =0 & & \text { otherwise }
\end{aligned}
$$

where $\varepsilon$ is an experimentation parameter and $n$ is the number of neighbours of strategy $(a, b)$. Thus, each strategy element has a propensity attached to it. And the propensity to choose a strategy in period $t+1$ is an update on the previous propensity of choice for that strategy (equation 5). This updating includes elements of discounting by (1- $\varphi)$ to reflect forgetting as well as the addition of new reinforcement $E_{c d}(j, R)$. For a strategy that was selected in the previous round, this additional reinforcement is equal to the reward $\mathrm{R}$ achieved, discounted by the need to experiment with "similar" or "neighbouring" strategies in the next round; this is indicated in the first line in equation (6). If the strategy whose propensity is being updated was a neighbour of a strategy selected in the previous round, then the new reinforcement is the result of experimentation (see second line in equation (6)). Note that since the mark-up has $n$ neighbouring strategies, the experimentation parameter is divided by $n$ in this line. Finally, as shown in the third line in equation (6), strategies that were not selected in the previous rounds and are not neighbouring a selected strategy, get no experimental spillovers.

The choice of a learnt bid curve is made in a probabilistic way in each round. The probability that a given strategy or $(a, b)$ value is chosen depends on that strategy's proportional share in

\footnotetext{
${ }^{6}$ For strategy sets without linear order, the generalization function should be specified as a two-step function. See Erev and Roth (1998, p. 863).
} 
the propensity sum for all strategies available to the bidder. Specifically, the probability that player $i$ uses his $(c, d)$ strategy is then given by:

$$
p_{i}^{c d}(t)=\frac{q_{i}^{c d}(t)}{\sum_{a} \sum_{b} q_{i}^{a b}(t)}
$$

Therefore, this learning algorithm has three parameters, namely, the recency parameter $(\varphi)$ used in equation (5), the experimentation parameter $(\varepsilon)$ used in equation (6) as well as a scale parameter (s) that determines the initial propensities $q_{1}^{a b}$. The parameter values that provided the best data for the 12 games studied in Erev and Roth (1998) were used in this study. These values are $0.1,0.2$ and 9 , respectively. The value of 0.1 for the recency parameter implies that propensities of choice get discounted by a factor of 0.9 between auction rounds. The experimentation parameter value of 0.2 implies that the reinforcement that a bid curve gets for being similar to a strategy selected in the previous round is $2.5 \%$ of the net reward achieved for the latter. The scale parameter does not appear in the above equations; it is used to set the initial (period 1) propensity values. The choice propensities are initially given uniform values and this uniform value is equal to the product of the scale parameter and the expected profit from any bidding round. The latter is harmlessly arbitrarily set at $10 \%$ of the bidder's cost for supplying her maximum capacity. The significance of the initial propensities is that they determine the overall scale from which propensities get reinforced and degraded as learning occurs. These can affect the speed at which the learning converges on particular choices. Sensitivity analyses show that our results are robust to variations in the parameter values of the learning algorithm. 


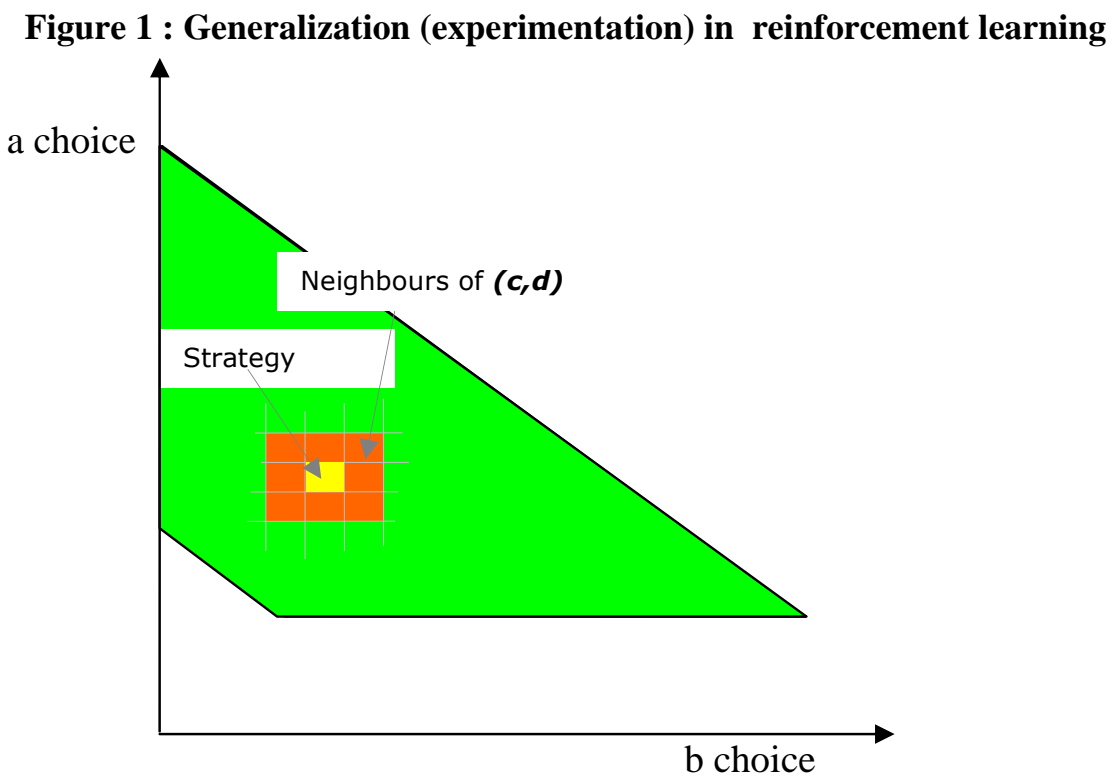

\section{Simulation results and discussion}

\section{Simulation settings}

Bidding under the Vickrey, discriminatory and uniform auctions was simulated in our computation experiments for different levels of competition and heterogeneity in the size and cost structures of the bidder population. The level of competition was varied by changing demand while keeping aggregate supply capacity constant at 4.0. Four levels of demand, namely, $0.5,1.0,1.5$ and 2.0 , were used. These correspond to $12.5 \%, 25 \%, 37.5 \%$ and $50 \%$ of the aggregate capacity available. Auction performance was simulated for the following four bidder populations (Table 2):

- population 1: a homogeneous population of bidders with similar capacity and costs, with a flat supply curve (constant marginal cost curve, $b^{0}=0$ )

- population 2: a population where $50 \%$ of the bidders are small capacity bidders and $50 \%$ are large capacity bidders, all with a flat supply curve $\left(b^{0}=0\right)$ 
- population 3: a homogeneous population with rising marginal cost curves $\left(b^{0}>0\right)$, and

- population 4: a highly heterogeneous population with bidders differentiated along two dimensions (capacity and the steepness of the marginal cost curves).

Table 2: description of the four populations of bidders

\begin{tabular}{|l|l|l|l|l|}
\hline & Bidders & Capacity & Entry price $\mathrm{a}_{\mathrm{i}}{ }^{0}$ & Supply slope $\mathrm{b}_{\mathrm{i}}{ }^{0}$ \\
\hline Population 1 & 8 identical bidders & 0.5 & 0.5 & 0 \\
\hline Population 2 & 4 small & 0.25 & 0.5 & 0 \\
& 4 large & 0.75 & 0.5 & 0 \\
\hline Population3 & 8 identical bidders & 0.5 & 0.5 & 0.5 \\
\hline Population 4 & 2 small -low cost: & 0.25 & 0.5 & 0.25 \\
& 2 small-high cost & 0.25 & 0.5 & 0.75 \\
& 2 large-low cost & 0.75 & 0.5 & 0.25 \\
& 2 large-high cost & 0.75 & 0.5 & 0.75 \\
\hline
\end{tabular}

\section{Convergence of simulated strategies}

Simulations are run over a large number of rounds until bidders have had ample time to learn and adjust their bids. What we are interested in are the bidders' convergence strategies, that is the pair $\left(a_{i}, b_{i}\right)$ obtained once convergence is reached. There are at least two ways to measure convergence in the choices that agents make. The first is to define convergence in terms of the stability of parameters that are selected. The second is to examine the distribution of probabilities of choice among the set of strategies that a bidder has. This second approach was employed in this study as it is more appropriate for the probabilistic nature of the choices that bidders make. To avoid premature termination of the learning process, it was required that the following two conditions hold for each bidder:

1) that the distribution of probabilities over choice strategies is unimodal, i.e. the probability of choice attached to the most likely strategy is at least 0.5 , and

2) that this probability is at least five times bigger than the second highest probability

For each experimental set up, 100 different replications were generated using different random seeds. A minimum of 1000 rounds were allowed before convergence was tested using these criteria. In $64 \%$ of the simulations, the convergence criteria were met within the 
first 2000 rounds and in $80 \%$ of the simulations within 5000 rounds. The simulation was allowed to run for a maximum of 20000 rounds if the convergence criteria were not met before that. The $20000^{\text {th }}$ round was reached without the convergence criteria being met only in $8 \%$ of the cases. An examination of the highest and second highest choice probabilities from the learning algorithm indicates that there was a predominant choice in most of the runs when the simulation was stopped.

The simulation results are discussed in the next section. We only analyse convergence results. Since all simulations involve 100 replications with different random seeds, the strategies and the performance of the auctions are evaluated based on the average values obtained from these 100 replications. First the bidding strategies observed are presented and compared to available theoretical predictions. Then the performance of the three auction format are

compared in terms of budgetary outlays per unit and in terms of the social efficiency of allocation as measured by the cost of production per unit.

\section{Results for a homogenous population of bidders with flat supply}

This population has the simplest structure. The bidders are homogeneous in capacity and the level of marginal cost is constant. Since the level of marginal cost is constant and identical for all bidders, the competition at any price level involves the entire aggregate capacity. The simulated bidding behaviour for this population (Table 3) indicates that bidding is truthful on the first unit (with a frequency of $99 \%$ or higher) in all auction formats regardless of the level of demand. The bidding strategy for the subsequent units was found to be dependent on the level of demand in the uniform auction but not in the discriminatory and Vickrey auctions. 
Table 3: Bidding strategy frequencies $(\%)$ for selected bidders: homogeneous population with constant marginal costs $(a=0.5, b=0)$

\begin{tabular}{lccccc}
\hline Auction type & $\begin{array}{l}\text { Demand } \\
\text { level }\end{array}$ & true a/true b & true a/higher b & higher a /true b & higher a/higher b \\
\hline \multirow{4}{*}{ Vickrey } & 0.5 & 85 & 15 & 0 & 0 \\
& 1 & 88 & 12 & 0 & 0 \\
& 1.5 & 87.8 & 11.9 & 0.3 & 0 \\
Discriminatory & 2 & 85.9 & 13.3 & 0.8 & 0 \\
& 0.5 & 5 & 95 & 0 & 0 \\
& 1 & 4.3 & 95.7 & 0 & 0 \\
Uniform & 1.5 & 3.5 & 96.5 & 0 & 0 \\
& 2 & 3.8 & 96 & 0.2 & 0 \\
& 1 & 5 & 95 & 0 & 0 \\
& 1.5 & 23.6 & 76.4 & 0 & 0 \\
\hline
\end{tabular}

Under the Vickrey format, learnt bidding behaviour generally conforms to the results predicted by theory which states that truthful bidding ("true a/true b") is a weakly dominant strategy. The frequency of truthful bidding is more than $85 \%$. In the remaining $15 \%$ of the cases, bidders bid truthfully on the first unit but overbid on the subsequent units ("true a/higher b"). The figures are summarized in Table 3 .

In discriminatory auctions, around $96 \%$ of selected bidders bid truthfully on the first unit and overbid on the following units (henceforth referred to as supply inflation). However, the literature (Englebrecht-Wiggans and Kahn 1998) indicates that the expected structural properties of equilibrium strategies are higher entry price and flat bidding on the following units (high flat bidding henceforth). A flattening of the supply curve improves bidder revenue as the prices received for infra-marginal units are brought closer to that of the marginal unit. So under this auction format, there is an incentive for bidders to organize their bids at the auction clearing price. However, when competition is tight, these flat supply curves are susceptible to price undercutting by rivals and the bidder can easily be priced out with small changes in others' bids. Under such circumstances, bidders have an incentive to ensure winning by bidding with truthful entry prices while at the same time earning positive net income by inflating prices on subsequent units. Thus, supply inflation is not precluded by 
theory (Krishna, 2002), and it is exactly what is observed in our simulations for the case of this homogenous populations.

It is only with the uniform format that the learnt behaviour changes greatly with the level of competition: for low demand levels, the bidding is comparable to the one observed in the discriminatory format (supply inflation), whereas for higher demand levels, the frequency of truthful bidding, as observed in the Vickrey format, increases. In a uniform auction, supply inflation allows the marginal bidder (the one setting the clearing price) and all other winners to make greater profits. It is therefore the behaviour expected by theory under uniform auctions. However, the propensity to bid more truthfully that is evident at lower completion levels can be explained by the fact that each bidder has a lower probability of being the price setter as the demand increases. Infra-marginal bidders have no incentives to inflate their bids as it does not impact the price they get.

\section{Results for a population of bidders with flat supply but heterogeneous sizes}

Here, we compare the bidding behaviours simulated in the simplest case described above with strategies observed for the case of a slightly more complex population of bidders (Table 4). Population 2 is made of bidders who all display identical constant marginal costs (flat supply) but having different sizes: $50 \%$ of agents with a low capacity $(\mathrm{ms}=0.25)$ and $50 \%$ of agents with a high capacity $(\mathrm{ms}=0.75)$. The total supply capacity, as well as the aggregate supply curve remain the same as in the homogenous base case $(a=0.5$ and $b=0)$.

Table 4: Bidding strategy frequencies $(\%)$ for selected bidders for demand of 1.5 : population of small and large bidders with constant marginal costs $(a=0.5, b=0)$

\begin{tabular}{llcccc}
\hline Auction type & Bidders & $\begin{array}{c}\text { true a/ } \\
\text { true b }\end{array}$ & $\begin{array}{c}\text { True a/ } \\
\text { higher b }\end{array}$ & $\begin{array}{c}\text { higher a/ } \\
\text { true b }\end{array}$ & $\begin{array}{c}\text { higher a/ } \\
\text { higher b }\end{array}$ \\
\hline \multirow{2}{*}{ Vickrey } & Small & 94.9 & 4.1 & 0 & 0 \\
\multirow{2}{*}{ Discriminatory } & Large & 83.4 & 15.2 & 1.4 & 0 \\
\multirow{2}{*}{ Uniform } & Small & 5.9 & 94.1 & 0 & 0 \\
& Large & 3.4 & 96.6 & 0 & 0 \\
& Small & 88.6 & 11.4 & 0 & 0 \\
& Large & 4.3 & 95.3 & 0 & 0 \\
\hline
\end{tabular}


The introduction of size heterogeneity has a very dramatic impact on bidding behaviours under the uniform auction. We observe great discrepancies between the strategies adopted by small and high capacity bidders, altering significantly the conclusions drawn for the homogeneous case. For high levels of demand, small bidders tend to adopt a truthful strategy whereas large bidders use a strategy of supply inflation. However, for lower levels of demand, small bidders display a mix of truthful and supply inflation strategies, i.e. the frequency of their bids on the combination (true a/higher b) goes up to $54 \%$ for $\mathrm{D}=12.5 \%$ of aggregate supply. The explanation is as follows. Large bidders are more likely to be price setters, especially for high levels of demand. They therefore tend to inflate the clearing price by overbidding on the last units. For lower levels of demand, small bidders have a greater chance to be price setters and therefore tend also to adopt aggressive overbidding.

Contrary to the uniform case, size does not have much influence on bidding strategies in the Vickrey and in the discriminatory auctions. Small and large capacity bidders adopt comparable strategies: truthful bidding in the Vickrey case and supply inflation in the discriminatory cases are the most frequent behaviours (above $80 \%$ and above $94 \%$, respectively). Furthermore, these observations are fairly insensitive to the level of demand or competition (although truthful behaviour tends to regress slightly under the Vickrey when competition levels decline).

\section{Results for homogeneous population of bidders with upward sloping supply}

When the marginal cost of production is positively sloped (Table 5), it is for the discriminatory format that major changes in bidding strategies are observed compared to what is observed when marginal costs are flat. For low demand levels, bidders display the same supply inflation behaviour as in the previous simulations (97\% on true $\mathrm{a} / \mathrm{higher} \mathrm{b}$ for $\mathrm{D}=0.5$ ) but when demand levels increase, the high flat bidding becomes increasingly prevalent, 
reaching a frequency of $74 \%$ (higher a/zero b) when the ratio of demand to total capacity is $50 \%$. The latter behaviour conforms to the theoretical predictions and is explained by reduced risks of being completely undercut by competitors when the demand level increases.

Table 5: Bidding strategy frequencies $(\%)$ for selected bidders for demand level 1.5: Homogeneous population with positively sloped marginal costs $(a=0.5, b=0.5)$

\begin{tabular}{lccccc}
\hline Auction type & $\begin{array}{c}\text { true a/ } \\
\text { true } \mathbf{b}\end{array}$ & $\begin{array}{c}\text { true a/ } \\
\text { higher } \mathbf{b}\end{array}$ & $\begin{array}{c}\text { higher a/ } \\
\text { true } \mathbf{b}\end{array}$ & $\begin{array}{c}\text { higher a// } \\
\text { higher } \mathbf{b}\end{array}$ & $\begin{array}{c}\text { higher a/ } \\
\text { lower } \mathbf{b} \text { (zero } \\
\mathbf{b} \text { ) }\end{array}$ \\
\hline Vickrey & 84.4 & 15.6 & 0 & 0 & $0(0)$ \\
Discriminatory & 4.3 & 35.7 & 0.4 & 0.4 & $59.2(59.2)$ \\
Uniform & 75.2 & 24.6 & 0 & 0 & $0.2(0.2)$ \\
\hline
\end{tabular}

With the other two auction formats, sincere bidding is prevalent at all levels of demand. The frequency of true a/true b bids is above $81 \%$ for the Vickrey and above $72 \%$ for the uniform. It is interesting to note that in both cases, the other frequent bidding strategy observed is supply inflation and that the frequency of this behaviour decreases when demand increases in the uniform format (from $27 \%$ for demand of 0.5 to $17.9 \%$ for demand of 2) whereas it remains relatively stable in the Vickrey format.

Results for population of bidders with heterogeneous sizes and supply slopes

In the final set of simulations, we include two sources of heterogeneity (size and marginal cost slopes) simultaneously. All bidders have the same entry price $(\mathrm{a}=0.5)$ but each falls into one of four categories depending on its capacity (ms) and true supply cost slopes (b). The four groups have two bidders each with the following characteristics:

Group A: small capacity and flatter supply curves $(\mathrm{ms}=0.25, \mathrm{~b}=0.25)$

Group B: large capacity and flatter supply curves $(\mathrm{ms}=0.75, \mathrm{~b}=0.25)$

Group C: small capacity and steeper supply curves $(\mathrm{ms}=0.25, \mathrm{~b}=0.75)$

Group D: large capacity and steeper supply curves $(\mathrm{ms}=0.75, \mathrm{~b}=0.75)$ 
Under the Vickrey auction, cases where bidders declare higher entry prices are almost nonexistent. Bidders predominantly bid their true entry prices ${ }^{7}$. And in at least $74 \%$ of the cases, the bids also reveal the true supply slopes resulting in truthful bidding. Between 18 and $24 \%$ of the time, bids combining true entry prices with higher slopes are observed under this auction. However, the different groups do not bid in exactly similar ways and the following differences are consistently observed among the groups. Smaller capacity bidders tend to be more truthful than their larger counterparts regardless of the slope of their true supply curves. Furthermore, bidders with shallower true supply curves tend to bid truthfully more frequently than equally sized bidders with steeper curves. These patterns can clearly be seen from the frequency results for the case of demand of 1.5 summarized in Table 6 . The frequencies of truthful bidding for the four groups are $91 \%, 75 \%, 86 \%$ and $56 \%$, respectively.

As with the results for the other populations, truthful bidding is almost non-existent with a discriminatory auction. The most predominant overbidding is the theoretically expected "high flat " supply bid which occurs with an increasing frequency as the level of competition decreases: it increases from $37 \%$ at a demand level of 1 to $69 \%$ at a demand level of 2 (see Figure 2). The only exceptions to this are large bidders with steep true supply curves who frequently adopt "supply inflation" strategies, especially for low demand levels. This behaviour is consistent with what has already been observed in more homogeneous population settings. It confirms that supply inflation is a strategy adopted by bidders who are likely to be totally priced out by rivals.

Bidding behaviour under the uniform auction varies with competition levels. At high competition levels (demand of 0.5) truthful bidding is the most frequent behaviour for all groups (77\% on average). This behaviour is higher for groups A, B, and C at 94\%, 80\% and $89 \%$, respectively. Only for big capacity and steep cost curve bidders (group D) is this

$7 \quad$ Only when the demand level is 2 does the frequency of bids with higher than true entry prices go above $1 \%$. At a demand level of 0.5 this rate is $0 \%$ and only $0.29 \%$ at a demand level of 1 . 
frequency below $50 \%$ as this group bids with truthful entry prices and inflated slopes. However, "supply inflation" becomes more frequent for all groups as the demand level increases to 1.0 but then declines as demand increases further where we observe a mixture of "truthful" and "high flat" strategies especially among groups B and C.

Table 6. Bidding strategy frequencies (\%) counts for demand level 1.5 for the population of bidders with heterogeneous sizes and supply slopes

\begin{tabular}{|c|c|c|c|c|c|}
\hline \multirow[b]{2}{*}{$\begin{array}{l}\text { Bidder } \\
\text { groups }\end{array}$} & \multicolumn{5}{|c|}{ Bidding strategies under Vickrey } \\
\hline & $\begin{array}{l}\text { true } a / \\
\text { true b }\end{array}$ & $\begin{array}{c}\text { true a/ } \\
\text { higher b }\end{array}$ & $\begin{array}{c}\text { higher a/ } \\
\text { true b }\end{array}$ & $\begin{array}{l}\text { higher a/ } \\
\text { higher b }\end{array}$ & $\begin{array}{c}\text { higher a/ } \\
\text { lower b } \\
(\text { zero b) }\end{array}$ \\
\hline Group A & 91.2 & 8.1 & 0.7 & 0 & 0 \\
\hline Group B & 74.9 & 22.7 & 0.6 & 0 & 1.8 \\
\hline Group C & 85.8 & 13.7 & 0 & 0 & 0.5 \\
\hline Group D & 56 & 43 & 0 & 0 & 0.6 \\
\hline \multirow[t]{3}{*}{ All bidders } & 77 & 22 & 0 & 0 & 1 \\
\hline & \multicolumn{5}{|c|}{ Bidding strategies under Discriminatory } \\
\hline & $\begin{array}{l}\text { true a/ } \\
\text { true b }\end{array}$ & $\begin{array}{c}\text { true } \mathrm{a} / \\
\text { higher } \mathrm{b}\end{array}$ & $\begin{array}{l}\text { higher } a / \\
\text { true } b\end{array}$ & $\begin{array}{l}\text { higher } a / \\
\text { higher } b\end{array}$ & $\begin{array}{c}\text { higher a/ } \\
\text { lower b } \\
\text { (zero b) }\end{array}$ \\
\hline Group A & 6 & 10 & 0 & 0 & 84 \\
\hline Group B & 7 & 9 & 1 & 0 & 83 \\
\hline Group C & 8 & 26 & 0 & 0 & 66 \\
\hline Group D & 1 & 98 & 0 & 0 & 1 \\
\hline \multirow[t]{3}{*}{ All bidders } & 5 & 36 & 0 & 0 & 59 \\
\hline & \multicolumn{5}{|c|}{ Bidding strategies under Uniform } \\
\hline & $\begin{array}{l}\text { true a/ } \\
\text { true b }\end{array}$ & $\begin{array}{c}\text { true a/ } \\
\text { higher b }\end{array}$ & $\begin{array}{c}\text { higher a/ } \\
\text { true b }\end{array}$ & $\begin{array}{l}\text { higher a/ } \\
\text { higher b }\end{array}$ & $\begin{array}{c}\text { higher a/ } \\
\text { lower b } \\
(\text { zero b) }\end{array}$ \\
\hline Group A & 91 & 6 & 1 & 0 & 2 \\
\hline Group B & 33 & 51 & 1 & 1 & 14 \\
\hline Group C & 84 & 13 & 0 & 0 & 3 \\
\hline Group D & 58 & 40 & 1 & 1 & 0 \\
\hline All bidders & 67 & 27 & 0 & 1 & 5 \\
\hline
\end{tabular}


(a) Learnt bid curves for bidder a bidder with capacity of 0.25 and slope of 0.25

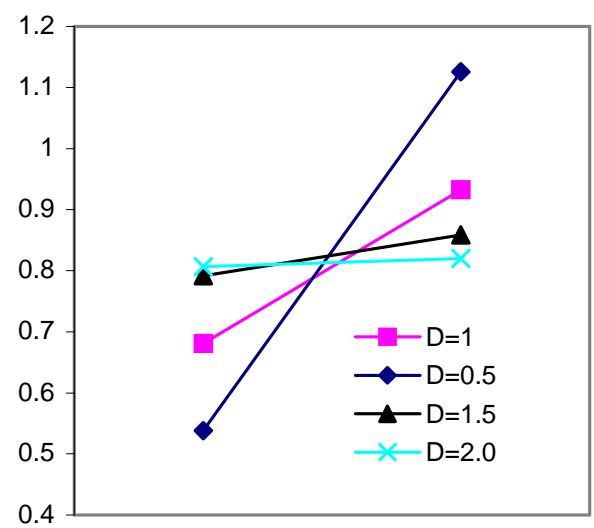

(b) Learnt bid curves for bidder a bidder with capacity of 0.75 and slope of 0.25

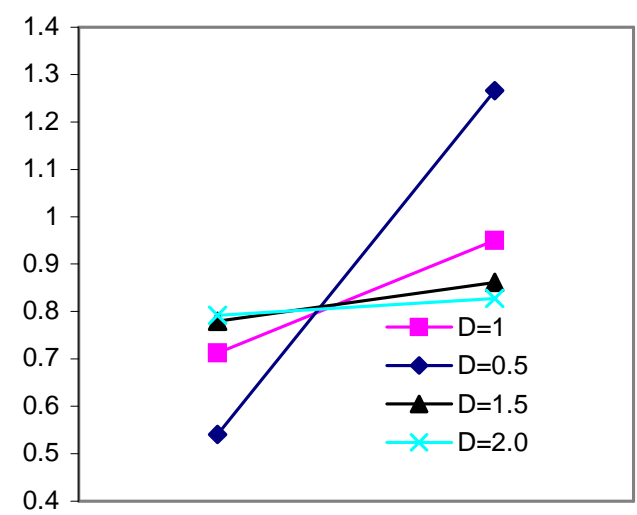

Figure 2. Bidding behaviour under a discriminatory auction, for different levels of competition: population of heterogeneous bidders with upward sloping supply cost curves

\section{Bidding strategies: a summary}

Examining the pattern of bidding behaviour across the different populations, the following general observations can be made.

1) For all types of bidder populations and demand levels considered here, the Vickrey auction leads to high frequencies of sincere bidding. This conforms with predictions from theoretical analysis. It can also be looked at as a confirmation that the learning algorithm used in the simulations does lead to coherent outcomes.

2) Overbidding is the norm under the discriminatory auction. The theoretically predicted high flat bidding (higher entry price and lower or zero slope) is observed in the case of bidder populations characterized by non-constant marginal cost curves. This behaviour becomes more predominant at lower levels of competition. Supply inflation (same entry price but higher supply slopes) is the predominant overbidding strategy under the discriminatory when the marginal cost of supply is constant. This behaviour (which is not precluded by theoretical analysis) allows the bidder to minimize the risk of being completely undercut by competitors. Therefore, this 
bidding strategy is rational when the level of competition is intense because demand is low and/or marginal cost is constant pitting every unit for sale against every other.

3) The uniform auction induces two types of strategies: truthful bidding and supply inflation. Supply inflation is observed mostly for high levels of competition and predominantly among bidders with large capacity and steep cost curves when the population is heterogeneous in size. The frequency of truthful bidding increases with increase in demand levels, especially among smaller capacity bidders who have a lower probability of being price setters.

4) When the context induces truthful bidding behaviour under the uniform auction, the frequency of truth telling is lower than that obtained under the Vickrey. Moreover, for both auction formats, the frequency of truthful bidding is higher for the group with most competitive cost structure (i.e. for group A than for group B).

\section{Nash equilibrium property tests of learnt strategies}

The learnt bids were tested for best reply properties by checking, for one bidder at a time, if there is no other strategy that allows the bidder to increase its net income. The convergence strategies constitute a Nash equilibrium (NE) if none of the eight players can improve on his net income using a bid other than the learnt one. The results are summarized in Table 7.

The percentage of learnt strategy choices that constitute a Nash equilibrium strategy set is high in the Vickrey at all demand levels for bidder populations 1 and 2. For these populations, between 82 to $95 \%$ percent of the experiments pass the NE test. For the populations with increasing marginal costs, this ratio is much lower. And for both discriminatory and uniform auctions, this rate is low regardless of the population. Finally, more choices constitute NE strategies when the level of competition is tighter (demand is low). These figures confirm that the multiplicity of possible equilibria induce coordination failures. Bidders learn to coordinate their overbidding when demand is high. And this coordination is easier when the population is 
heterogeneous and the clearing price is set by fewer bidders. However, these coordinated bids do not constitute best reply strategies as individual bidders can improve their net incomes through unilateral deviation. With the Vickrey, for example, coordinating bidding choices with others so that the clearing price is high benefits all bidders. However, a bidder's net income might improve (but would never go down) if it reverts to a more truthful bidding strategy given the choices of its competitors. In the discriminatory auction, a bidder's revenue depends on his own bid, providing the bidder with the incentive to deviate if other bidders were to keep their bids fixed. Under the uniform, the bidder's revenue can depend on its own bidding strategy. Therefore, a bidder might have the same incentives to defect or 'free ride' on the price coordination choices of other bidders.

Table 7: Proportion of learnt bidding strategies that pass the Nash equilibrium tests (\%): Vickrey (V), Discriminatory (D) and Uniform (U) auctions

\begin{tabular}{|c|c|c|c|c|c|c|c|c|c|c|c|c|}
\hline \multirow[b]{2}{*}{ Demand } & \multicolumn{3}{|c|}{ Population 1} & \multicolumn{3}{|c|}{ Population 2} & \multicolumn{3}{|c|}{ Population 3} & \multicolumn{3}{|c|}{ Population 4} \\
\hline & $\mathbf{V}$ & D & $\mathbf{U}$ & $\mathbf{V}$ & D & $\mathbf{U}$ & $\mathbf{V}$ & D & $\mathbf{U}$ & $\mathbf{V}$ & D & $\mathbf{U}$ \\
\hline 0.5 & 95 & 91 & 30 & 90 & 71 & 72 & 30 & 25 & 29 & 50 & 34 & 48 \\
\hline 1.0 & 97 & 13 & 20 & 84 & 22 & 60 & 18 & 1 & 9 & 11 & 5 & 17 \\
\hline 1.5 & 83 & 14 & 17 & 82 & 11 & 8 & 15 & 0 & 10 & 8 & 0 & 5 \\
\hline 2.0 & 86 & 14 & 15 & 82 & 10 & 11 & 13 & 0 & 8 & 2 & 2 & 2 \\
\hline
\end{tabular}

\section{Auction performance}

The performance of an auction is measured using the following two criteria: budgetary outlay and the total production costs. The former measures the monetary transfers from the buyer to the bidders. The latter measures the auction's social cost efficiency. From a social welfare perspective, the auction outcomes are more efficient if the product purchased is sourced from lower cost producers. The second criterion is relevant only for the last two experiments (populations 3 and 4) as any allocation is equally efficient when marginal costs are constant and identical for all bidders as in populations 1 and 2.

The analysis of auction efficiency confirms what has been observed with bidding strategies. The Vickrey is the most efficient for all types of populations. The discriminatory is the least 
efficient. These results are related to the relative frequency of truthful bidding displayed under the three formats.

Judging by budgetary outlay, the Vickrey auction is the least expensive in almost all settings. This advantage of the Vickrey is very clear when bidders have constant marginal costs (populations 1 and 2), especially for high levels of demand. See Figure 3. For populations of increasing marginal cost bidders (population 3 and 4), the budgetary outlays in the Vickrey and in the uniform are almost the same when demand is low. For higher demand levels in heterogeneous populations (populations 2 and 4), however, the performance of the uniform auction declines, due mainly to the strategies of large bidders who tend to drive the auction clearing price up by overbidding on the last units. See Figure 4.

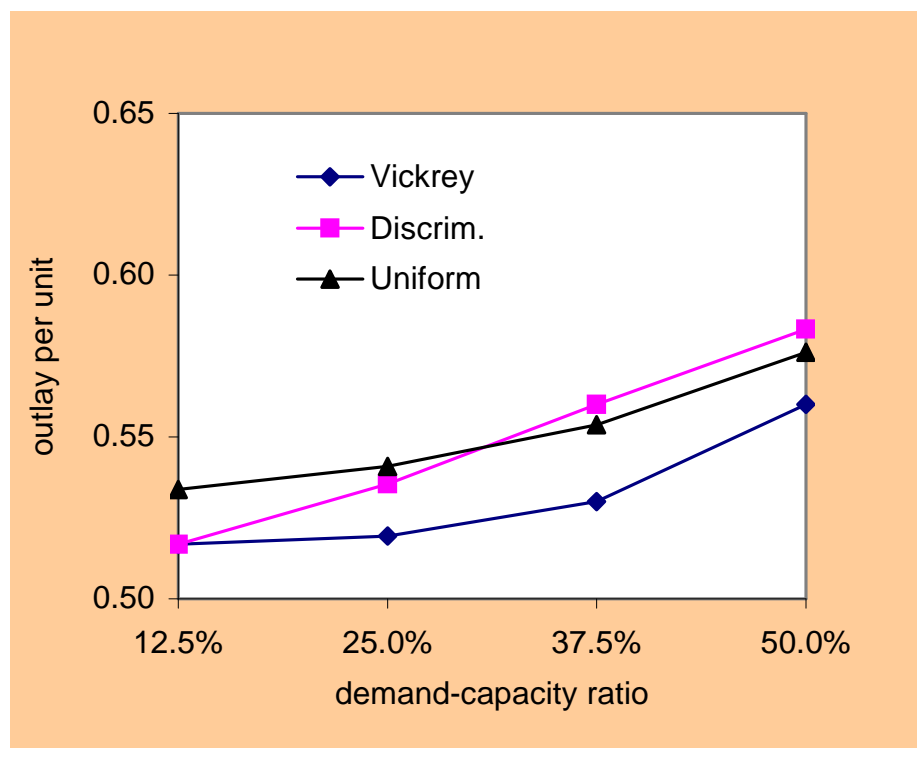

Figure 3. Outlay per unit for different levels of competition for the population of homogeneous bidders with flat supply cost curves 


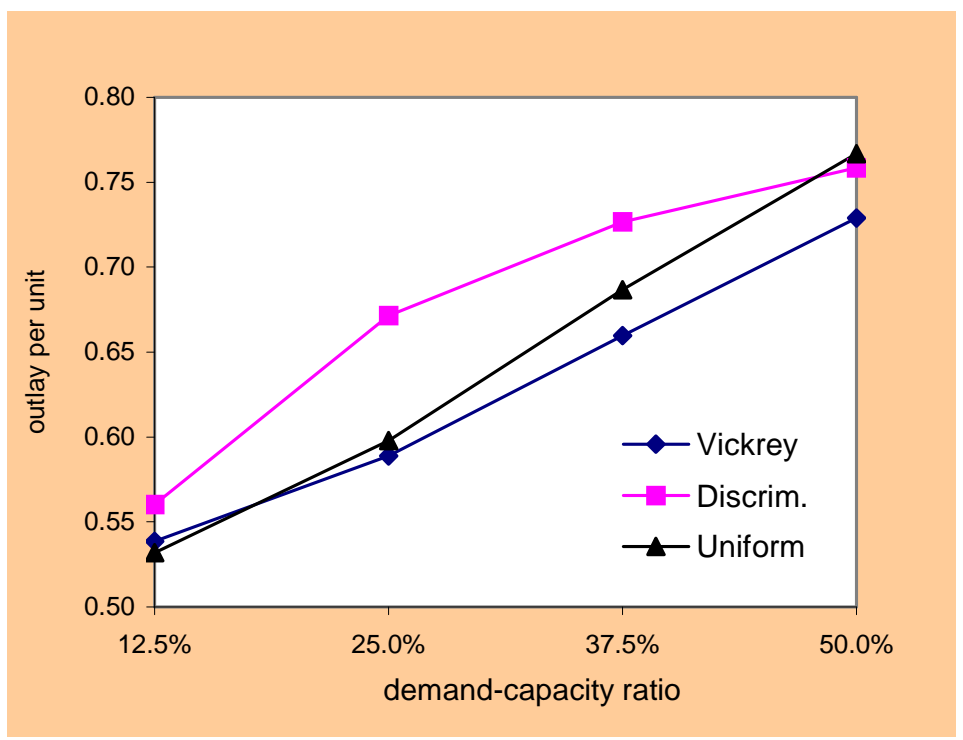

Figure 4. Outlay per unit for different levels of competition for the population of heterogeneous bidders with upward sloping supply cost curves

The discriminatory auction format is generally the most expensive auction but with the following two qualifications. For high competition levels, the discriminatory often performs as well as the Vickrey especially when the population is homogeneous. For low competition levels with populations which are heterogeneous in size, the discriminatory can perform better than the uniform.

Table 8. Auction performance for bidder population 4

\begin{tabular}{|c|c|c|c|c|c|c|}
\hline \multirow[t]{3}{*}{$\begin{array}{l}\text { Performance } \\
\text { measure }\end{array}$} & \multicolumn{3}{|c|}{ Summary Performance Measures } & \multicolumn{3}{|c|}{$\begin{array}{c}\text { Summary Relative Performance } \\
\text { Measures }\end{array}$} \\
\hline & \multicolumn{3}{|c|}{ Demand: 0.5} & \multicolumn{3}{|c|}{ Demand: 0.5} \\
\hline & Vickrey & Discriminatory & Uniform & Vickrey & Discriminatory & Uniform \\
\hline Outlay per unit & 0.539 & 0.560 & 0.532 & 1.025 & 1.095 & 1.016 \\
\hline \multirow[t]{3}{*}{ Cost per unit } & 0.516 & 0.519 & 0.515 & 1.008 & 1.014 & 1.006 \\
\hline & \multicolumn{3}{|c|}{ Demand: 1} & \multicolumn{3}{|c|}{ Demand: 1} \\
\hline & Vickrey & Discriminatory & Uniform & Vickrey & Discriminatory & Uniform \\
\hline Outlay per unit & 0.589 & 0.672 & 0.598 & 1.068 & 1.283 & 1.093 \\
\hline \multirow{3}{*}{ Cost per unit } & 0.532 & 0.545 & 0.533 & 1.016 & 1.041 & 1.018 \\
\hline & \multicolumn{3}{|c|}{ Demand: 1.5} & \multicolumn{3}{|c|}{ Demand: 1.5} \\
\hline & Vickrey & Discriminatory & Uniform & Vickrey & Discriminatory & Uniform \\
\hline Outlay per unit & 0.660 & 0.727 & 0.687 & 1.126 & 1.357 & 1.194 \\
\hline \multirow[t]{3}{*}{ Cost per unit } & 0.551 & 0.556 & 0.554 & 1.029 & 1.038 & 1.035 \\
\hline & \multicolumn{3}{|c|}{ Demand: 2} & \multicolumn{3}{|c|}{ Demand: 2} \\
\hline & Vickrey & Discriminatory & Uniform & Vickrey & Discriminatory & Uniform \\
\hline Outlay per unit & 0.729 & 0.759 & 0.767 & 1.162 & 1.379 & 1.252 \\
\hline Cost per unit & 0.568 & 0.569 & 0.572 & 1.034 & 1.035 & 1.040 \\
\hline
\end{tabular}


The average performance figures for population 4 are presented in Table 8 . The table also presents performance measures relative to what would have occurred under truthful bidding (last 3 columns). These relative figures help us assess the relative distortion of true values under the three formats. This distortion is highest for program outlay under the discriminatory auction; program outlay under bidder learning ranges from $110 \%$ to $138 \%$ of what it would have been under truthful bidding. This figure ranges from $102 \%$ to $116 \%$ for the Vickrey auction and from $102 \%$ to $125 \%$ for the uniform auction. Therefore, the level of overpayment can be significant even in the case of the Vickrey auction where bidding is predominantly but not completely truthful. Efficiency losses are relatively small, in a range of $0.8 \%$ to $4 \%$.

\section{Conclusions}

Economic theory does not provide an analytical description of the equilibrium bidding strategies under multi-unit uniform and discriminatory auctions. The choice of auction format continues to be a controversial issue. The objective of this paper is to contribute towards filling this knowledge gap by using computational experiments to simulate bidding behaviour and auction performance for three pricing formats: uniform, discriminatory and generalized Vickrey auctions.

The paper started by discussing theoretical predictions for the three auction types and the knowledge gaps that exist. Findings from some studies using human experiments were also discussed. An agent-based model was then formulated to simulate bidding among a population of agents that use a reinforcement learning algorithm to update their bids based on individual experience. The bidders learn over a strategy space with two dimensions: the intercept and slope parameters of their bid function. The experiments are undertaken for four different demand levels (ranging in magnitude from $12.5 \%$ to $50 \%$ of aggregate supplier 
capacity) and for four different types of bidder populations, with the most heterogeneous one consisting of four groups of bidders differentiated by size and marginal cost slopes.

Our results indicate that bidding behaviour cannot be completely characterized by auction format. It also depends on the nature of the bidder population and the level of competition. In particular, bidding strategies in a uniform auction are extremely sensitive to the heterogeneity of size amongst bidders. Uniform auctions induce two types of strategies: truthful bidding and supply inflation (i.e. true entry price but increasing overbidding on the subsequent units). When the population of bidders is heterogeneous in capacity, dramatic differences in bidding behaviours occur under the uniform format. Supply inflation is observed mostly for high levels of competition and predominantly for large capacity bidders. It is the strategy adopted by the bidders who are likely to be the price setters. On the contrary, when bidders are less likely to be price setters, they tend to remain truthful and "free-ride" on the risks taken by their bigger or more expensive counterparts.

The discriminatory auction, on the other hand, never leads to truthful bidding: two types of overbidding behaviours are observed: supply inflation and high flat bidding (i.e. high leant entry price and flat supply bid). The high flat bidding expected by theory is found for bidders with increasing marginal costs, when levels of competition are low. However, supply inflation of the type observed in the uniform auction is a frequent strategy when true marginal costs are constant or when competition levels are high. Our results provide evidence of such bidding behaviour among all types of bidders at high competition levels, and even at high demand levels for bidders with less competitive cost structures. This bidding behaviour has also been observed in human experimental studies (Engelmann and Grimm 2003). An intuitive explanation can be provided for this deviation from the high flat bidding predicted by theory. High flat bids have the capacity to improve bidder revenue as the prices received for all units sold are brought closer. However, this strategy increases the risk that the bidder is completely 
priced out by rivals. Therefore, when a bidder faces stiff competition as a result of its similarity with others or because of its less competitive cost structure, a strategy of supply inflation rather than high flat bidding allows it to avoid zero gain outcomes.

The picture provided by these simulations is more complex than the partial view that the theory provides in relation to the structural properties of equilibrium strategies under the three formats. It indicates that attention should be granted to the heterogeneity of the bidding population, not only in terms of cost structure but also in terms of size.

The analysis of the relative performance of auctions in terms of budget outlays also delivers a strong message. The discriminatory auction, which is commonly used in practice, is in most cases the most expensive format. Vickrey is the least expensive procurement auction in most cases. The reluctance of auctioneers to use this action might be related to its relative complexity, especially in the multi-unit case. The uniform auction can perform better than the discriminatory auction for most levels of competition. Therefore, procuring agencies and policymakers would need to seriously consider alternatives to the discriminatory auction.

There are several emerging auction markets where multi-unit auctions could be applied in Australia. Auctions for allocating conservation contracts are currently of great interest throughout Australia. The National Market-Based Instruments Pilot Program of the National Action Plan for Salinity and Water Quality ${ }^{8}$ is in its second round; and, both rounds have included several pilots trialing conservation auctions. However, none of these auctions have been multi-unit auctions although the lumpy bid nature of single-unit bids is identified to be a problem for private landholders (see, for example, Chan, Laplagne. and Appels (2003)). Moreover, all auction trials have focused only on one payment format, the discriminatory auction, and there has been little consideration of

\footnotetext{
${ }^{8}$ A description of the pilot program is available here: http://www.napswq.gov.au/mbi/index.html
} 
alternative pricing formats. Another potential application area for multi-unit auctions

is the buyback of water rights from irrigators in order to restore environmental flows.

The buyback of forest harvest rights for environmental protection purposes (e.g. in

Tasmania) is also an area where properly designed multi-unit auctions can be used to

improve budgetary and allocative efficiency outcomes.

\section{References}

Alemsgeest, P. Noussair S. and Olson M. (1998), 'Experimental comparisons of auctions under single and multi-unit demand', Economic Inquiry, 36, 87-97.

Andreoni, J. and Miller J.H. (1995), 'Auctions with Artificial Adaptive Agents' Games and Economic Behavior, 58, 211-21.

Ausubel, L. M. (2005), 'An efficient ascending-bid auction for multiple objects', American Economic Review, 94, 1452-75.

Ausubel L.M. and Cramton P. (2002), 'Demand reduction and inefficiency in multi-unit auctions', Working paper, University of Maryland

Back K and Zender J. (1993), 'Auctions of divisible goods: on the rationale for the treasury experiment', Review of Financial Studies, 6, 733-64.

Binmore K. and Swierzbinski J. (2000), 'Treasury auctions: uniform or discriminatory?', Review of Economic Design, 5, 387-410

Bower J, and Bunn D.W (2001) 'Experimental analysis of the efficiency of uniform price versus discriminatory auctions in the England and Wales electricity market', Journal of Economic Dynamics and Control, 25, 561-592.

Bunn, D.W. and Oliveira F.S (2001), 'Agent-based simulation: An application to the new electricity trading arrangements of England and Wales', IEEE transactions on Evolutionary Computation, 5, 493-503.

Camerer, C.F. (2003). Behavioral Game Theory: Experiments in Strategic Interaction. Princeton University Press: Russell Sage Foundation, New York

Chakraborty I. (2006), 'Characterization of equilibrium in pay-as-bid auctions for multiple units', Economic Theory, 29(1), 197-211

Chan C. Laplagne P. and Appels D. (2003), The Role of Auctions in Allocating Public Resources, Staff Research Paper, Productivity Commission, Melbourne, 144 pages.

Duffy, J. (2006), 'Agent-based models and human-subject experiments', in Judd K.L. and Tesfatsion L. (eds) The Handbook of Computational Economics, vol. 2. Elsevier: Amsterdam.

Engelbrecht-Wiggan, R. and Kahn C. (1998), 'Multi-unit auctions with uniform prices', Economic Theory, 12, 227-239

Engelmann, D. and Grimm V. (2003), 'Bidding behaviour in multi-unit auctions - an experimental investigation and some theoretical insights', Working paper, CSERGE.

Epstein, J.M. and Axtell R. (1996), Growing Artificial Societies: Social sciences from the Bottom up, Brookings Institution Press: Washington DC

Erev, I. and Roth A.E. (1998), 'Predicting how people play games with unique, mixed strategy equilibria', American Economic Review, 88, 848-81.

Hailu, A. and Schilizzi S. (2004), 'Are auctions more efficient than fixed price schemes when bidders learn?', Australian Journal of Management, 29, 147-68.

Kagel, J. and Levin D. (2001), 'Behavior in multi-unit demand auctions: experiments with uniform price and dynamic Vickrey auctions', Econometrica, 69 (2), 413-454 
Krishna, V. (2002), Auction Theory, Academic Press, Elsevier: London, 303 pages.

List, J. and Lucking-Reiley D. (2000), 'Demand reduction in multi-unit auctions: evidence from a sportscard field experiment', American Economic Review, 90 (4), 961-72

Nicolaisen, J., Petrov V., and Tesfatsion L. (2001), 'Market power and efficiency in a computational electricity market with discriminatory double-auction pricing', IEEE transactions on Evolutionary Computation, 5, 504-23.

Noussair C. (1995), 'Equilibria in a multi-object uniform sealed bid auction with multi-unit demands', Economic Theory, 5(2), 337-351

Roth, A.E. and Erev I. (1995), 'Learning in extensive form games: experimental data and simple dynamic models in the intermediate term', Games and Economic Behavior, 8, 164212.

Swinkels, J. (1999), 'Asymptotic efficiency for discriminatory private value auctions', Review of Economic Studies, 66, 509-28

Tenorio, R. (1993), 'Revenue equivalence and bidding behaviour in a multiunit auction market: An empirical analysis', The Review of Economics and Statistics, 75, 302-14

Tenorio, R. (1999), 'Multiple unit auctions with strategic price-quantity decisions', Economic Theory, 13, 247-60

Tesfatsion, L. (2002), 'Agent-Based Computational Economics: Growing Economies from the Bottom Up', Artificial Life, 8, 55-82.

Wilson, R. (1979), 'Auctions of shares', The Quarterly Journal of Economics, 93, 675-89

Wolfram, C. (1998), 'Strategic bidding in a multiunit auction: An empirical analysis of bids to supply electricity in England and Wales', Rand Journal of Economics, 29, 703-25. 